\title{
Protonation Scheme for some Triaza Macrocycles Studied by Potentiometry and NMR Spectroscopy
}

\author{
Carlos F. G. C. Geraldes, ${ }^{a, *}$ A. Dean Sherry, ${ }^{b}$ M. Paula M. Marques, ${ }^{a}$ M. Carmen Alpoim ${ }^{a}$ and \\ Sergio Cortes ${ }^{b}$ \\ a Chemistry Department, University of Coimbra, 3000 Coimbra, Portugal \\ b Chemistry Department, University of Texas at Dallas, PO Box 830688, Richardson, Texas 75083-0688, USA
}

\begin{abstract}
A series of triaza macrocyclic tricarboxylate ligands with ring sizes of nine to twelve (NOTA, DETA, UNTA and DOTRA) have been synthesized. Their acid-base properties and protonation sequence have been established and compared with those of the corresponding cyclic triamines and trimethyl cyclic triamines, using potentiometric measurements and ${ }^{1} \mathrm{H}$ NMR pH titrations. The first protonation constant of the carboxylate ligands is very high, and larger than the value for the parent cyclic amines. It is also very sensitive to the presence of $\mathrm{Na}^{+}$ions in solution. The first two protonation constants correspond to protonation of the ring nitrogens, and their increase with ring size is non-monotonic, reflecting $\mathrm{pH}$-dependent conformational effects. These effects, due to electrostatic interactions as well as to hydrogen bond formation, caused difficulties in the application of methods (previously used for noncyclic polyaminocarboxylates) to obtain the protonation sequence from the ${ }^{1} \mathrm{H} N M R$ pH titrations, similar to a previous occurrence for tetraaza macrocycles. By studying the $\mathrm{pH}$ dependence of the shielding parameters, $C_{N}$ and $C_{N^{\prime}}$, the protonation sequences were then obtained. For each of the four compounds studied, two nitrogen atoms are protonated before the carboxylate groups. Formation of hydrogen bonds between protonated nitrogens and non-protonated carboxylates affects the basicity of the latter, reducing the flexibility of these ligands in certain $\mathrm{pH}$ intervals.
\end{abstract}

There has been considerable interest recently in the development of new macrocyclic polyaminopolycarboxylate ligands which, by forming lanthanide(III) chelates of high thermodynamic and kinetic stability, can be used as NMR shift probes for biological systems $^{1}$ or as contrast agents for magnetic resonance imaging. ${ }^{2}$ Of these, the carboxylate ligands derived from triaza and tetraaza macrocyclic amines have been of much interest to us, although mixed polyazapolyoxa derivatives, such as diazatrioxa- ${ }^{3-6}$ and diazatetraoxa- ${ }^{6-8}$ derivatives have been extensively studied by other groups. Tetraaza macrocyclic tetracarboxylates such as 1,4,7,10-tetraazacyclododecane- $N, N^{\prime}, N^{\prime \prime}, N^{\prime \prime \prime}$-tetraacetic acid (DOTA) and larger ring analogues have been previously studied in both their acid-base ${ }^{9-11}$ and metal complexation ${ }^{10,12-14}$ properties, using potentiometry and NMR spectroscopic techniques. Similarly, the triaza macrocyclic ligand 1,4,7-triazacyclononane- $N, N^{\prime}, N^{\prime \prime}$-triacetic acid (NOTA) and some of its transition metal and lanthanide(III) complexes have also been studied using different techniques. ${ }^{13,15-22}$ The stability constants of the NOTA and DOTA chelates of the lanthanides, which have slow formation kinetics, have been determined using a colorimetric method. ${ }^{23}$ The nuclear relaxivity of solvent water of their $\mathrm{Gd}^{3+}$ chelates has also been investigated using the Nuclear Magnetic Relaxation Dispersion (NMRD) technique. ${ }^{24}$ It was found that $\mathrm{Gd}(\mathrm{NOTA})$ has a higher relaxivity but much lower thermodynamic and kinetic stability than Gd(DOTA) ${ }^{-}$. In an effort to combine the high stability and relaxivity properties in one single chelate, the metal binding properties of triaza macrocyclic carboxylate analogues of NOTA containing larger rings are currently being investigated. ${ }^{25}$

In this work we report the synthesis, acid-base properties and protonation sequence for the triaza NOTA analogues (see Fig. 1), 1,4,7-triazacyclodecane- $N, N^{\prime}, N^{\prime \prime}$-triacetic acid (DETA) 1,4,8-triazacycloundecane- $N, N^{\prime}, N^{\prime \prime}$-triacetic acid (UNTA) and 1,5,9-triazacyclododecane- $N, N^{\prime}, N^{\prime \prime}$-triacetic acid (DOTRA) as well as of the corresponding cyclic triamines and trimethyl cyclic triamine derivatives. These results are compared with previous studies on the cyclic triamines ${ }^{26-30}$ and on the triazacyclononane derivatives. ${ }^{19,20,22}$

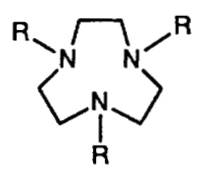

$\mathrm{R}=\mathrm{H}$
$\mathrm{R}=\mathrm{Me}$
$\mathrm{R}=\mathrm{CH}_{2} \mathrm{CO}_{2} \mathrm{H}$

[9]ane $\mathrm{N}_{3}$ $\mathrm{Me}_{3}[9] \mathrm{ane} \mathrm{N}_{3}$ NOTA<smiles>[R]N1CCCN([R])N(C)CCC1</smiles>

[11]ane $\mathrm{N}_{3}$ $\mathrm{Me}_{3}[11] \mathrm{aneN}$ UNTA

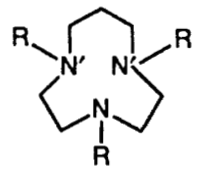

[10]ane $\mathrm{N}_{3}$ $\mathrm{Me}_{3}[10] \mathrm{an} \Theta \mathrm{N}_{3}$ DETA



[12]ane $\mathrm{N}_{3}$ $\mathrm{Me}_{3}[12] \mathrm{aneN}$ DOTRA
Fig. 1 Structures of the cyclic triamine compounds studied

\section{Experimental}

Synthesis and Characterization of the Ligands.-Cyclic amines. 1,4,7-Triazacyclononane ([9]ane $\mathrm{N}_{3}$, see Fig. 1); 1,4,7triazacyclodecane $\left([10]\right.$ ane $\left.\mathrm{N}_{3}\right) ; 1,4,8$-triazacycloundecane $\left([11]\right.$ ane $\left.\mathrm{N}_{3}\right)$ and 1,5,9-triazacyclododecane $\left([12] \mathrm{aneN}_{3}\right)$ were synthesized either by the method of Richman-Atkins ${ }^{25,26,31-35}$ or by cyclization of the linear tosylamides over $\mathrm{K}_{2} \mathrm{CO}_{3} \cdot{ }^{36}$ The amines were isolated and stored as their trihydrobromide salts. $^{36}$

Methylated amines. $\mathrm{Me}_{3}[9] \mathrm{aneN}_{3}$ and $\mathrm{Me}_{3}[10] \mathrm{aneN}_{3}$ were obtained by treating the respective cyclic amines with n-butyllithium (6 equiv.) in dry ether, $\uparrow$ under $\mathrm{N}_{2}$ at $-78^{\circ} \mathrm{C}$. After being quenched with excess iodomethane, the reaction mixtures were stirred at room temperature for $30 \mathrm{~min}$, washed with brine, dried over anhydrous $\mathrm{Na}_{2} \mathrm{SO}_{4}$ and concentrated under reduced pressure to give the expected products in $90 \%$

$\dagger$ Ether refers to diethyl ether throughout. 
yields. $\mathrm{Me}_{3}$ [12] $\mathrm{aneN}_{3}$ was obtained by reductive methylation of [12] ane $\mathrm{N}_{3}$ as follows: to the trihydrobromide of the amine $(50 \mathrm{mg}, 0.178 \mathrm{mmol})$ in dry methanol $\left(3 \mathrm{~cm}^{3}\right)$ was added $\mathrm{KOH}$ $(9 \mathrm{mg})$. After dissolution of the pellets, anhydrous formaldehyde $(1 \mathrm{mmol})$ in dry methanol $\left(2 \mathrm{~cm}^{3}\right)$ was added and the reaction mixture was stirred overnight at room temperature. $\mathrm{NaCNBH}_{3}$ (or $\mathrm{NaBH}_{4}$ ) (6 equiv.), in dry methanol $\left(5 \mathrm{~cm}^{3}\right)$ was then added and the reaction mixture was stirred for an additional $2 \mathrm{~h}$. The solvent was removed under reduced pressure, chloroform was added and, after alkaline work up ( $\mathrm{pH} c a .12)$, the $\mathrm{pH}$ was lowered to 1-2 and the organic layer was extracted with water. The aqueous layer was concentrated under reduced pressure and the residue was carefully washed with ethanol to give white crystalline $\mathrm{Me}_{3}[12] \mathrm{aneN}_{3}$ in $60 \%$ yield. $\mathrm{Me}_{3}[11] \mathrm{aneN}_{3}$ could not be synthesized by either of the methylation methods described above. $N$-Alkylation of the three nitrogens of the larger triaza rings is very slow in aqueous media because the monoprotonated acid is slow and difficult to deprotonate. $^{30}$

1,4,7-Triazacyclononane- $\mathrm{N}, \mathrm{N}^{\prime}, \mathrm{N}^{\prime \prime}$-triacetic acid. NOTA was prepared from the trihydrobromide of [9] $\mathrm{aneN}_{3}$ by addition of bromoacetic acid, using published procedures. ${ }^{12,20}$ After the reaction was complete the $\mathrm{pH}$ was adjusted to 3.5 with concentrated $\mathrm{HBr}$. White crystals, obtained after addition of ethanol and cooling, were washed with ethanol and dried under vacuum at $70^{\circ} \mathrm{C}$ (yield $90 \%$ ). This form of NOTA, containing $2 \mathrm{~mol}$ of $\mathrm{NaBr}$ salt, was purified using a Dowex 50W-X2 (200400 mesh) cation exchange chromatography column, eluted with a $1.5-6 \mathrm{~mol} \mathrm{dm}^{-3} \mathrm{HCl}$ gradient, in $30 \mathrm{~cm}^{3}$ fractions. All the fractions collected were concentrated under reduced pressure, and the compound was recrystallized from absolute ethanol, dried under vacuum at $150^{\circ} \mathrm{C}$ and obtained as the trihydrochloride derivative of NOTA.

1,4,7-Triazacyclodecane- $\mathrm{N}, \mathrm{N}^{\prime}, \mathrm{N}^{\prime \prime}$-tris(acetic acid methyl ester). [10] ane $\mathrm{N}_{3}$ was first isolated by dissolving the amine salt in $1 \mathrm{~mol} \mathrm{dm}^{-3} \mathrm{NaOH}$, extracting with chloroform $(\times 3)$, followed by removal of the solvent and drying under vacuum. Then, in a typical preparation, 1,4,7-triazacyclodecane $(0.184 \mathrm{~g}$, $1.29 \mathrm{mmol})$ was dissolved in dichloromethane $\left(5 \mathrm{~cm}^{3}\right)$ and diisopropylethylamine $\left(10 \mathrm{~cm}^{3}\right)$. A solution of methyl bromoacetate $(0.60 \mathrm{~g}, 3.92 \mathrm{mmol})$ in dichloromethane $\left(5 \mathrm{~cm}^{3}\right)$ was then added dropwise to the amine solution with stirring at room temperature. The mixture was stirred for an additional $12 \mathrm{~h}$, the solvent was evaporated under reduced pressure, and the residue redissolved in chloroform $\left(10 \mathrm{~cm}^{3}\right)$. The solution was washed with water $\left(3 \times 5 \mathrm{~cm}^{3}\right)$, dried over $\mathrm{NaOH}$ pellets and filtered. Evaporation of the chloroform gave the product in $78 \%$ yield $(0.36 \mathrm{~g})$ as a yellow oil, which was used without further purification: $\delta_{\mathrm{H}}\left(200 \mathrm{MHz}, \mathrm{CDCl}_{3}\right) 1.26(\mathrm{p}, 2 \mathrm{H}), 2.60$ $(\mathrm{m}, 8 \mathrm{H}), 2.88(\mathrm{~m}, 4 \mathrm{H}), 3.17(\mathrm{~s}, 4 \mathrm{H}), 3.27(\mathrm{~s}, 2 \mathrm{H})$ and $3.54(\mathrm{~s}$, $9 \mathrm{H}) ; \delta_{\mathrm{C}}\left(50 \mathrm{MHz}, \mathrm{CDCl}_{3}\right) 25.20,47.74,50.95,51.01,52.47,54.52$, $54.69,55.10$ and 172.31 .

1,4,7-Triazacyclodecane- $\mathrm{N}, \mathrm{N}^{\prime}, \mathrm{N}^{\prime \prime}$-triacetic acid. The trimethylated ester was mixed with water $\left(8 \mathrm{~cm}^{3}\right)$ and the $\mathrm{pH}$ adjusted to $\leqslant 1$ with $2 \mathrm{~mol} \mathrm{dm}^{-3} \mathrm{HCl}$. The mixture was allowed to reflux for $12 \mathrm{~h}$, cooled and concentrated under reduced pressure to $1-2 \mathrm{~cm}^{3}$. The $\mathrm{pH}$ was adjusted to $7-8$ using $2 \mathrm{~mol}$ $\mathrm{dm}^{-3} \mathrm{NaOH}$ and the solution was loaded on to a Dowex-1X8 anion exchange chromatography column in the chloride form (100-200 mesh). The column was washed with water and then eluted with a $0.2 \mathrm{~mol} \mathrm{dm}{ }^{-3} \mathrm{HCl}-\mathrm{H}_{2} \mathrm{O}$ gradient $\left(500 \mathrm{~cm}^{3}\right)$, monitoring the eluent absorbance at $524 \mathrm{~nm}$. The collected fractions were concentrated and examined by ${ }^{1} \mathrm{H}$ and/or ${ }^{13} \mathrm{C}$ NMR spectroscopy. Freeze-drying typically afforded the hydrochloride salt of DETA in $80 \%$ yield; m.p. $63^{\circ} \mathrm{C}$ (decomp.); $\delta_{\mathrm{H}}\left(200 \mathrm{MHz}, \mathrm{D}_{2} \mathrm{O}, \mathrm{pH}\right.$ ca. 0.5, HOD at $\left.4.80 \mathrm{ppm}\right) 2.32$ (br, $\left.2 \mathrm{H}\right)$, $3.44(\mathrm{br}), 3.54(\mathrm{br}), 3.86(\mathrm{~s}, 2 \mathrm{H})$ and $4.09(\mathrm{~s}, 4 \mathrm{H}) ; \delta_{\mathrm{H}}$ (same sample, $\left.80^{\circ} \mathrm{C}\right) 2.90(\mathrm{p}, 2 \mathrm{H}), 3.89(\mathrm{br} \mathrm{s}, 8 \mathrm{H}), 4.00(\mathrm{t}, 4 \mathrm{H}), 4.31(\mathrm{~s}$,
$2 \mathrm{H})$ and $4.44(\mathrm{~s}, 4 \mathrm{H}) ; \delta_{\mathrm{C}}\left(50 \mathrm{MHz}, \mathrm{D}_{2} \mathrm{O}, \mathrm{pH} c a .0 .5\right.$, ref. $p$ dioxane at $67.0 \mathrm{ppm}) 20.91,50.86,51.95,53.85,56.19,56.77$, 169.42 and 172.85 (Found: C, 37.7; H, 6.7; N, 9.8; Cl, 16.0; O, 29.8. Calc. for $\mathrm{C}_{13} \mathrm{H}_{33} \mathrm{~N}_{3} \mathrm{O}_{6} \cdot 2 \mathrm{HCl} \cdot 2 \mathrm{H}_{2} \mathrm{O}: \mathrm{C}, 36.92 ; \mathrm{H}, 6.86 ; \mathrm{N}$, 9.86; $\mathrm{Cl}, 16.63 ; \mathrm{O}, 30.02$ ).

1,4,8-Triazacycloundecane- $\mathrm{N}, \mathrm{N}^{\prime}, \mathrm{N}^{\prime \prime}$-tris(acetic acid methyl ester). UNTA-trimethyl ester was synthesized using procedures identical to that for DETA-trimethyl ester. $\delta_{\mathrm{H}}(200 \mathrm{MHz}$, $\left.\mathrm{CDCl}_{3}\right) 1.54(\mathrm{p}, 4 \mathrm{H}), 2.60-2.90(\mathrm{~m}, 12 \mathrm{H}), 3.25(\mathrm{~s}, 2 \mathrm{H}), 3.34$ $(\mathrm{s}, 4 \mathrm{H})$ and $3.69(\mathrm{~s}, 9 \mathrm{H}) ; \delta_{\mathrm{C}}\left(50 \mathrm{MHz}, \mathrm{CDCl}_{3}\right) 24.41,49.56,50.49$, $51.12,52.53,54.09,55.11,172.21$ and 172.40 .

1,4,8-Triazacycloundecane-N, $\mathrm{N}^{\prime}, \mathrm{N}^{\prime \prime}$-triacetic acid. UNTA, obtained by hydrolysis of the ester as described for DETA, was isolated as a hygroscopic mixture of dihydrochloride hydrates, as suggested by elemental analysis: m.p. $133^{\circ} \mathrm{C}$ (decomp.); $\delta_{\mathrm{H}}\left(200 \mathrm{MHz}, \mathrm{D}_{2} \mathrm{O}, \mathrm{pH}\right.$ ca. 1.0, HOD at $\left.4.80 \mathrm{ppm}\right) 2.17(\mathrm{br})$, $2.34(\mathrm{br}), 3.54(\mathrm{br}), 3.84(\mathrm{br})$ and $4.14(\mathrm{br} s) ; \delta_{\mathrm{C}}(50 \mathrm{MHz}$, $\mathrm{D}_{2} \mathrm{O}, \mathrm{pH}$ ca. 1.0, ref. p-dioxane at $\left.67.0 \mathrm{ppm}\right)$ 19.64, 50.70, 52.53 (br), 55.63, 56.39 (br), 56.90, 169.95 and 171.91 (br) (Found: $\mathrm{C}, 40.7 ; \mathrm{H}, 6.7 ; \mathrm{N}, 10.1 ; \mathrm{Cl}, 16.1 ; \mathrm{O}, 26.4$. Calc. for $\mathrm{C}_{14} \mathrm{H}_{25} \mathrm{~N}_{3} \mathrm{O}_{6} \cdot 2 \mathrm{HCl} \cdot 0.5 \mathrm{H}_{2} \mathrm{O}: \mathrm{C}, 40.68 ; \mathrm{H}, 6.83 ; \mathrm{N}, 10.17 ; \mathrm{Cl}$, 17.16; O, 25.16).

1,5,9-Triazacyclododecane- $\mathrm{N}, \mathrm{N}^{\prime}, \mathrm{N}^{\prime \prime}$-triacetic acid. DOTRA was synthesized as previously described. ${ }^{25}$

Potentiometric Measurements.- $\mathrm{pH}$ Titrations were performed using an Orion Research Model 701A pH meter. The glass electrode was calibrated by measuring the EMF of a series of standard buffers with $\mathrm{pH}$ values within the range 2.00-12.72. The chelates were dissolved in $0.1 \mathrm{~mol} \mathrm{dm}^{-3} \mathrm{NaCl}$ and titrated with NBS standard $0.100 \mathrm{~mol} \mathrm{dm}^{-3} \mathrm{NaOH}$ (from Aldrich) and in some cases were also dissolved in $0.1 \mathrm{~mol} \mathrm{dm}^{-3}$ tetramethylammonium chloride, made basic with tetramethylammonium hydroxide and titrated with NBS standard $0.100 \mathrm{~mol} \mathrm{dm}^{-3} \mathrm{HCl}$ (from Aldrich). All samples were kept under $\mathrm{N}_{2}$ during the $\mathrm{pH}$ titrations and the sample temperature was maintained at $25 \pm 0.5^{\circ} \mathrm{C}$. The protonation constants of the ligands $\mathrm{L}$ are defined as $\mathrm{K}_{i}=\left[\mathrm{H}_{i} \mathrm{~L}\right] /\left[\mathrm{H}_{i-1} \mathrm{~L}\right]\left[\mathrm{H}^{+}\right]$, where $i=1,2,3 \ldots$. Protonation constants were obtained from the potentiometric data using a simplex non-linear regression algorithm ${ }^{37}$ written in BASIC. The highest and lowest protonation constants of DETA and UNTA could be determined to within \pm 0.1 units based upon duplicate measurements while the middle values were reproducible to within \pm 0.02 units.

NMR Measurements.-Solutions of the ligands $(0.01 \mathrm{~mol}$ $\mathrm{dm}^{-3}$ ) for NMR $\mathrm{pH}$ titrations were made up in $\mathrm{D}_{2} \mathrm{O}(99.8 \%$ from Sigma), and the $\mathrm{pD}$ was adjusted with $\mathrm{DCl}, \mathrm{CO}_{2}$-free $\mathrm{NaOD}$ (Sigma) or a $1.106 \mathrm{~mol} \mathrm{dm}^{-3}$ standardized KOD solution $\left(\mathrm{CO}_{2}\right.$ free). The final $\mathrm{pH}$ was determined with a Radiometer PHM 64 pH meter equipped with a Philips GA 110 -NS electrode and corrected for a deuterium isotope effect using $\mathrm{pD}=\mathrm{pH}+0.4 .^{38}$ The hydrogen electrode used in this work allows a reliable and accurate determination of the proton activity over an extended $\mathrm{pH}$ range. ${ }^{1} \mathrm{H}$ and broad band protondecoupled ${ }^{13} \mathrm{C}$ spectra were obtained, respectively, at 200 and $50.1 \mathrm{MHz}$ on a JEOL FX-200 or a Varian XL-200 FT spectrometer. Some proton spectra were obtained at $500 \mathrm{MHz}$ on a General Electric GE-500 spectrometer. ${ }^{1} \mathrm{H}$ and ${ }^{13} \mathrm{C}$ shifts were referenced to either t-butyl alcohol or dioxane as internal standards, or TMS as an external standard. Probe temperatures were accurate to $\pm 0.5^{\circ} \mathrm{C}$.

\section{Results and Discussion}

Protonation Constants.-Table 1 summarizes the protonation constants of the triaza macrocyclic tricarboxylate ligands obtained by potentiometry at $25^{\circ} \mathrm{C}$. These are compared with 
Table 1 Protonation constants of triaza macrocyclic ligands, obtained by potentiometry (at $25^{\circ} \mathrm{C}$ )

\begin{tabular}{|c|c|c|c|c|c|c|c|}
\hline \multirow{4}{*}{$\begin{array}{l} \\
\log K_{1} \\
\log K_{2} \\
\log K_{3}\end{array}$} & \multicolumn{2}{|c|}{$[9]$ ane $\mathrm{N}_{3}{ }^{a}$} & \multicolumn{2}{|c|}{$[10] \operatorname{aneN}_{3}{ }^{a}$} & \multicolumn{2}{|c|}{$[11] \operatorname{aneN}_{3}{ }^{a}$} & {$[12] \operatorname{aneN}_{3}^{a}$} \\
\hline & \multirow{2}{*}{\multicolumn{2}{|c|}{$\begin{array}{c}10.4 \\
6.82\end{array}$}} & 12.02 & & \multicolumn{2}{|c|}{11.96} & \multirow{2}{*}{$\begin{array}{r}12.60 \\
7.57\end{array}$} \\
\hline & & & 6.59 & & 7.6 & & \\
\hline & \multicolumn{2}{|l|}{$g$} & $g$ & & \multicolumn{2}{|c|}{$g$} & 2.41 \\
\hline & \multicolumn{3}{|c|}{ NOTA $^{b, c, d}$} & \multicolumn{2}{|c|}{ DETA $^{e}$} & UNTA $^{e}$ & DOTRA $^{f}$ \\
\hline & $b$ & $c$ & $d$ & & & & \\
\hline $\log K_{1}$ & 11.41 & 11.3 & 10.77 & 13.5 & & 13.9 & 12.8 \\
\hline $\log K_{2}$ & 5.74 & 5.59 & 6.03 & 6.12 & & 7.20 & 7.55 \\
\hline $\log K_{3}$ & 3.16 & 2.88 & 3.16 & 3.69 & & 3.40 & 3.65 \\
\hline $\log K_{4}$ & 1.71 & $g$ & 1.96 & 2.3 & & 1.7 & 2.1 \\
\hline
\end{tabular}

${ }^{a}$ From ref. $29\left(0.1 \mathrm{~mol} \mathrm{dm}{ }^{-3} \mathrm{KNO}_{3}\right){ }^{b}$ From ref. $19\left(0.1 \mathrm{~mol} \mathrm{dm}{ }^{-3}\right.$ $\left.\mathrm{NaNO}_{3}\right) \cdot{ }^{c}$ From ref. $20\left(0.1 \mathrm{~mol} \mathrm{dm}^{-3} \mathrm{NaClO}_{4}\right) .{ }^{d}$ From ref. $22(1.0 \mathrm{~mol}$ $\left.\mathrm{dm}^{-3} \mathrm{NaClO}_{4}\right) .{ }^{e}$ This work $\left(0.1 \mathrm{~mol} \mathrm{dm}{ }^{-3} \mathrm{NaCl}\right){ }^{f}$ From ref. $25(0.1$ mol $\left.\mathrm{dm}^{-3} \mathrm{NMe}_{4} \mathrm{Cl}\right)$. ${ }^{g} \mathrm{Not}$ determined. ${ }^{h}$ Obtained by spectrophotometry (ref. 25)

the values reported previously for the corresponding macrocyclic triamines. The observed enhancement of the basicity of the ring nitrogens with increase of ring size from nine to twelve members has been discussed previously. ${ }^{27,29}$ This effect can only in part be explained by decreased electrostatic repulsion in the larger rings. In fact, the non-monotonic increase of the protonation constants with ring size may reflect conformational effects, the possibility of different tautomeric forms of the monoand diprotonated forms of [10] $\mathrm{aneN}_{3}$ and [11] ane $\mathrm{N}_{3}$, or the trapping of hydrogen bonded $\mathrm{H}_{3} \mathrm{O}^{+}$ions by the larger rings (see below). 27,29

Substitution of acetate groups on each nitrogen atom of the parent cyclic amine sharply increases the first protonation constant of NOTA, DETA and UNTA, but not as much in DOTRA. $^{25}$ The values of the first protonation constant presented in Table 1 for DETA and UNTA were obtained in the present work, in the presence of $0.1 \mathrm{~mol} \mathrm{dm}^{-3} \mathrm{NaCl}$, whereas one of the values quoted for NOTA, $\log K_{1}=11.41,{ }^{19}$ was obtained in the presence of $0.1 \mathrm{~mol} \mathrm{dm}^{-3} \mathrm{NaNO}_{3}$. Larger concentrations of $\mathrm{Na}^{+}$are reponsible for the decrease of this protonation constant, e.g. $\log K_{1}=10.77$, in $1.0 \mathrm{~mol} \mathrm{dm}^{-3}$ $\mathrm{NaClO}_{4}{ }^{22}$ In the absence of $\mathrm{Na}^{+}$ions, the first protonation constant of these chelates may be significantly higher. The first protonation constant of DOTRA, $\log K_{1}=12.8$, has been obtained by spectrophotometry and NMR pH titrations, ${ }^{23}$ as it may be too high to determine accurately by potentiometry. In this work we found that this situation also applies to NOTA, DETA and UNTA (see below). As shown by ${ }^{1} \mathrm{H}$ NMR shifts (see below), protonation first occurs at one of the ring nitrogens, whose basicity is increased by the negative charge of the neighbouring ionized carboxylate group. The appending methylenephosphonate groups of the macrocyclic polyazaphosphonates has a similar effect on the first protonation constant for this type of chelate. ${ }^{39}$

Acetate substitution has only a small effect upon the second protonation constants of these ligands ( $\log K_{2}$ for NOTA shows the largest decrease, Table 1). Since the second protonation also occurs at a ring nitrogen (see below), this must result from a combination of inductive effects of the acetates and the formation of internal hydrogen bonds in the mono- and diprotonated forms of the ligands. The next two protonations occur at the carboxylate groups ${ }^{20}$ and are basically independent of ring size.

NMR Studies of Ligand Protonation.-The macroscopic protonation constants do not indicate the sequence of ligand protonation sites. The microscopic protonation scheme can be obtained by following the NMR chemical shifts of the ligand methylene protons as a function of $\mathrm{pH}$, since the protonation of donor atoms generally results in a deshielding of the non-labile hydrogens and changes in chemical shifts can indicate the site of protonation. ${ }^{20}$ Such $\mathrm{pH}$ titrations, obtained in a broad $\mathrm{pH}$ interval, are shown in Figs. $2-4$, for the macrocyclic triamines, the trimethylated derivatives and the triacetates, respectively. For these latter compounds, the presence of $\mathrm{Na}^{+}$ions markedly affects their proton spectra and titration curves at basic $\mathrm{pH}$ values. This indicates that, at $\mathrm{pH}>11, \mathrm{Na}^{+}$ions bind within the cavity of these chelates, and, by interacting with both the nitrogen and carboxylate oxygen donor atoms, induce low frequency proton shifts, similar to those previously observed for macrocyclic polyazaphosphonates. ${ }^{39}$

All spectra of the $\mathrm{Na}^{+}$-free ligands showed single resonances for each magnetically equivalent group of nuclei over the entire $\mathrm{pH}$ range, indicating rapid exchange between all protonated species, $\mathrm{H}_{n} \mathrm{~L}$. We generally observed $\mathrm{pH}$-dependent linewidth effects on the trimethyl and triacetate derivatives (but not on the simple triamines), which corresponds to slow interconversion processes between the various conformations of those macrocycles, due to nitrogen inversion, as discussed below.

Under conditions of fast proton exchange among the various protonated species, $\mathbf{H}_{n} \mathrm{~L}$, the observed averaged chemical shift of nucleus $i$ is given by $\delta_{\text {obs }}^{i}=\Sigma_{n} \delta_{n}^{i} X_{\mathrm{H}_{n} \mathrm{~L}}$, where $\delta_{n}^{i}$ are the intrinsic chemical shifts of the $\mathrm{H}_{n} \mathrm{~L}$ species and $X_{\mathrm{H}_{n} \mathrm{~L}}$ is the mole fraction of each species. Using the protonation constants obtained by potentiometry (Table 1 ), the $\delta_{n}^{i}$ values can be calculated using a multiple linear regression program, which minimizes the sums of the squares of the deviation between the observed and calculated $\delta_{\text {obs }}^{i}$ values. ${ }^{39}$ In each set of shift data (Figs. 2-4), fits can be performed by fitting the protonation constants to values obtained by potentiometry in $\mathrm{NMe}_{4} \mathrm{Cl}$ or by also allowing optimization of the $\log K_{i}$ values. As the ionic strength was not kept constant throughout the NMR pH titrations, the best overall fits were obtained by allowing optimization of the $\log K_{i}$ values. For this reason, the calculated protonation constants, shown in Table 2 , are subject to greater uncertainty than potentiometrically determined values.

The proton intrinsic shifts obtained for the various $\mathrm{H}_{n} \mathrm{~L}$ forms can be used to calculate the percentage protonation of the nitrogen or oxygen sites, using the method of Sudmeier and Reilley. ${ }^{40}$ According to this empirical procedure, the observed shifts of the ligand protons a-f (see Figs. $2-4), \delta_{o b s}^{i}$, are a function of the intrinsic shifts of the fully deprotonated form of the ligand $\left(\delta_{\mathrm{o}}^{i}\right)$; the fraction of protonation of the nitrogen $(\mathrm{N})$ and of the carboxylate $(\mathrm{O})$ sites at each $\mathrm{pH}\left(f_{\mathrm{N}}\right.$ and $f_{\mathrm{O}}$, respectively); the change in proton chemical shift due to $\alpha$-carboxylate protonation $\left(C_{\mathrm{O}}\right)$; and protonation of a $\mathrm{N}$ atom in the $\alpha$ position $\left(C_{\mathrm{N}}\right)$ or in the $\beta$ position $\left(C_{\mathrm{N}^{\prime}}\right)$ relative to the $\mathrm{CH}_{2}$ group under study. The average number of ligand bound protons at the $\mathrm{N}$ ligand basic sites is $n_{\mathrm{N}}=\alpha_{\mathrm{N}} f_{\mathrm{N}}+\alpha_{\mathrm{O}} f_{\mathrm{O}}$, where $\alpha_{N}$ and $\alpha_{\mathrm{O}}$ are the number of equivalent $\mathrm{N}$ and $\mathrm{O}$ sites.

For linear polyaminocarboxylates, Sudmeier and Reilley ${ }^{40}$ showed that the shift effects of protonation at various basic sites were additive, and obtained a $\mathrm{pH}$-independent set of shielding constants, $C_{\mathrm{O}}=0.20, C_{\mathrm{N}}=0.75$ and $C_{\mathrm{N}^{\prime}}=0.35 \mathrm{ppm}$. However, in macrocyclic compounds, where there are pHdependent conformational changes, that additivity is only maintained if the shielding constants are themselves pHdependent. $^{9,11,20}$

Macrocyclic Triamines and Trimethylated Derivatives.-The plots of the proton chemical shifts $v s$. $\mathrm{pH}$ for the triaza macrocycles and the trimethylated derivatives are shown in Figs. 2 and 3 , respectively. The assignment of the proton resonances is quite straightforward, taking into account their 
(a)

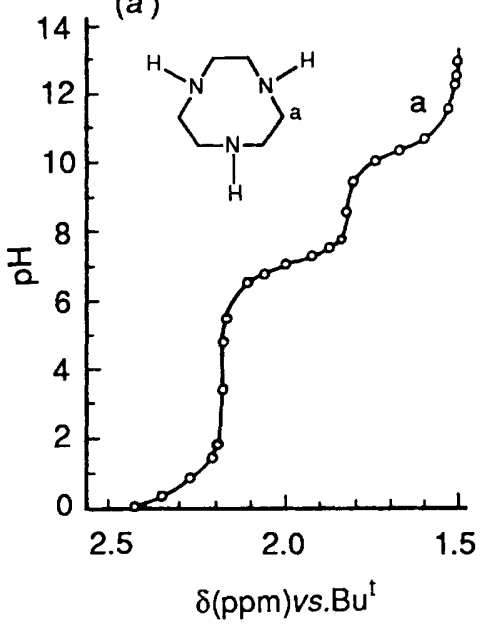

(b)

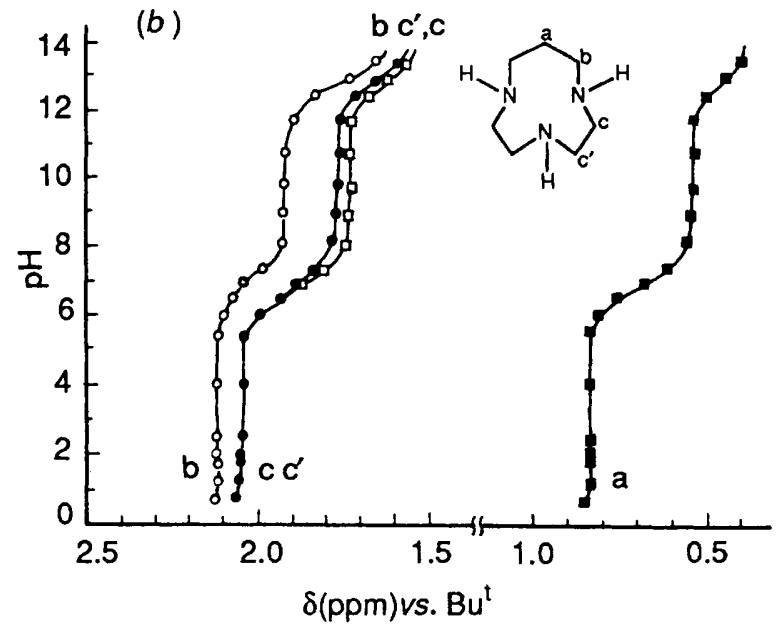

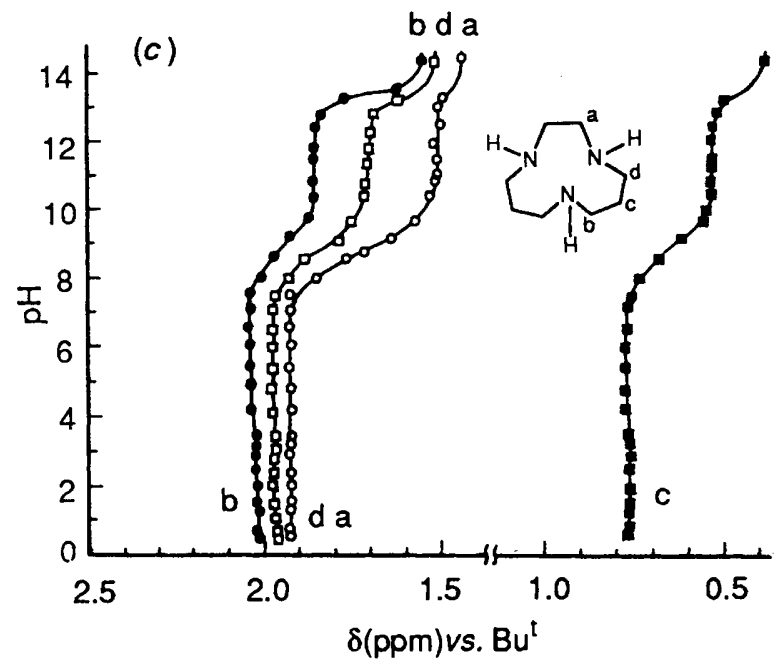



Fig. $2{ }^{1} \mathrm{H}$ NMR titration curves $(\delta$ as a function of $\mathrm{pH})$, using $\mathrm{NaOD}$, for the triaza macrocyclic amines: $(a)[9]$ aneN $\mathrm{N}_{3} ;(b)[10]$ aneN ${ }_{3} ;(c)[11]$ ane $\mathrm{N}_{3}$; (d) [12] ane $\mathrm{N}_{3}$

area ratios and multiplet patterns. Hence, the methyl protons give narrow singlets; the same is true for some methylene protons in symmetrically positioned ethylenediamine bridges [a of NOTA, Fig. 4(a)]. However, in less symmetrical situations, those methylene protons give, for some $\mathrm{pH}$ values, $\mathrm{AA}^{\prime} \mathrm{BB}^{\prime}$ or $\mathrm{AA}^{\prime} \mathrm{XX}^{\prime}$ multiplets [e.g. $\mathrm{c}$ and $\mathrm{c}^{\prime}$ of $[10] \mathrm{aneN}_{3}$, Fig. $2(b)$, and $\mathrm{Me}_{3}[10]$ aneN $\mathrm{N}_{3}$, Fig. 3(b)]. The methylene protons of propylenediamine bridges in position $\alpha$ relative to nitrogen atoms give triplets $\left[\right.$ e.g. b of $[10] \mathrm{aneN}_{3}$ and $[12] \mathrm{aneN} \mathrm{N}_{3}$, Fig. $2(b, d)]$, while those in the $\beta$ position give rise to quintuplets at lower frequency [e.g. a of $[10] \operatorname{aneN}_{3}$, Fig. $\left.2(b)\right]$. The relative assignments of resonances $b$ and $d$ of $[11] \mathrm{aneN}_{3}$ and of $c$ and $c^{\prime}$ of [10]aneN $\mathrm{N}_{3}$ and $\mathrm{Me}_{3}[10] \mathrm{aneN}_{3}$ were made on the basis of the calculated percent protonations $f_{\mathrm{N}}$ and $f_{\mathrm{N}^{\prime}}$ (Table 3) and similar situations described for tetraaza macrocycles. ${ }^{14}$

The NMR titration curves of the seven amines studied show the effect of stepwise protonation of the three nitrogens of the molecules $\mathrm{L}$, with formation of the species $\mathrm{HL}^{+}, \mathrm{H}_{2} \mathrm{~L}^{2+}$ and $\mathrm{H}_{3} \mathrm{~L}^{3+}$. Three inflections are observed in some cases, centred at values shown in Table 2, which should correspond to their three protonation constants (the third inflection, corresponding to formation of $\mathrm{H}_{3} \mathrm{~L}_{3}^{+}$, was not observed for ligands [10]ane $\mathrm{N}_{3}$, [11] ane $\mathrm{N}_{3}$ and $\mathrm{Me}_{3}[10] \mathrm{aneN}_{3}$. In some cases, the protonation constants obtained by NMR titrations were significantly larger than those obtained by potentiometry. In the case of the high $\log K_{1}$ values of [10]ane $\mathrm{N}_{3}$ and [11] ane $\mathrm{N}_{3}$, this fact may reflect large ionic strength effects. However, a similar effect on $\log K_{2}$ of [11] ane $\mathrm{N}_{3}$ is difficult to explain.

In the symmetric amines [Figs. $2(a, d)$; Figs. $3(a, c)$ ] all the $\mathrm{CH}_{2}$ and $\mathrm{CH}_{3}$ protons exhibit the same behaviour, corresponding to equal simultaneous partial protonation of the three ring nitrogens. This is not observed for the asymmetric amines [Figs. 2(b,c); Fig. 3(b)] where the non-equivalent nitrogens are protonated differently at intermediate $\mathrm{pH}$ values.

Comparison of the approximate protonation constants obtained by NMR spectroscopy for the compounds studied (Table 2) indicates that methylation of the macrocyclic amines generally leads to larger $\log K_{1}$ and smaller $\log K_{2}$ values. These relative values and the absolute values of $\log K_{2}(5.2-8.7)$ are very different from those observed for the tetraaza macrocycles, ${ }^{9,11,41}$ reflecting the very different protonation processes of triaza and tetraaza macrocyclic amines. ${ }^{42}$ In the cases which 

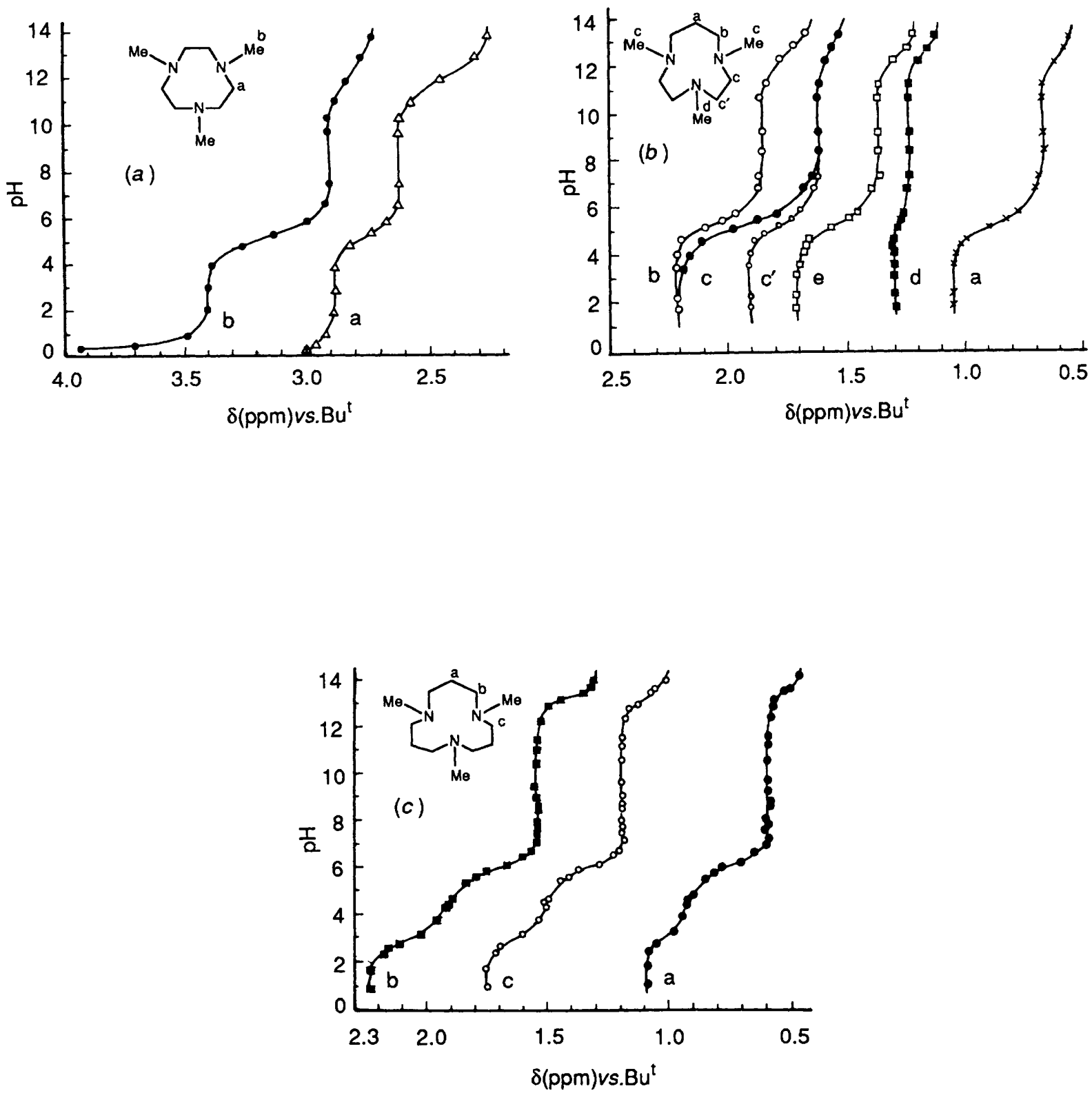

Fig. $3{ }^{1} \mathrm{H}$ NMR titration curves, using $\mathrm{NaOD}$, for the trimethylated triaza macrocyclic amines: (a) $\mathrm{Me}_{3}[9] \mathrm{aneN} \mathrm{N}_{3} ;\left(\right.$ b) $\mathrm{Me}_{3}[10] \mathrm{aneN} \mathrm{N}_{3} ;(c)$ $\mathrm{Me}_{3}[12] \mathrm{aneN}_{3}$

were measured, nitrogen methylation does not seem to affect the $\log K_{3}$ values.

When the method of Sudmeier and Reilley ${ }^{40}$ is applied to the analysis of the titration curves of Figs. 2 and 3, the shielding constants corresponding to protonation at the nitrogen atoms can be calculated. These shielding constants are $\mathrm{C}_{\mathrm{N}}\left(-\mathrm{CH}_{2} \mathrm{NR}_{2}\right.$ or $\left.-\mathrm{CH}_{2} \mathrm{NHR}\right), \mathrm{C}_{\mathrm{N}^{\prime}}\left(-\mathrm{CH}_{2} \mathrm{CH}_{2} \mathrm{NR}_{2}\right.$ or $\left.-\mathrm{CH}_{2} \mathrm{CH}_{2} \mathrm{NHR}\right)$ and $\mathrm{C}_{\mathrm{N}}^{m}\left(-\mathrm{CH}_{3} \mathrm{NR}_{2}\right)$. Table 3 shows those calculated shielding constants, obtained for well-defined protonation stages of the macrocyclic triamines, with total number of equivalents of acid added $n=1-3$. It also shows the calculated protonation fractions at the two types of nitrogen atoms, $N\left(N_{1}\right)$ and $N^{\prime}\left(N_{2}\right.$ or $\left.N_{3}\right)$, defined by the symmetry of asymmetric amines. Those protonation fractions, $f_{\mathrm{N}}$ and $f_{\mathrm{N}^{\prime}}$, show clearly, for each value of $n$, that the non-equivalent nitrogen atoms of the asymmetric amines are protonated differently for values of $n=1$ and 2 . That is clearly seen for [10]ane $\mathrm{N}_{3}$, where, for $n=1$, and to a lesser extent for $n=2$, there is a marked preference for protonation at $\mathrm{N}^{\prime}(86 \%$ and $79 \%$, of total available protons, for $n=1$ and $n=2$, respectively). Methylation of the nitrogens, e.g. $\mathrm{Me}_{3}[10] \mathrm{aneN}_{3}$ slightly decreases this preference for $n=1$
$(76 \%)$, but increases it for $n=2(83 \%)$. In the case of [11] ane $\mathrm{N}_{3}$, the first protonation shows a marked preference for the $\mathrm{N}$ site $(52 \%)$, but this preference decreases for $n=2(37 \%)$. As a whole, these preferential protonation sites correspond to the possibility of formation of six-membered rings within the protonated macrocycle, through hydrogen bonding between two of the three nitrogen atoms of the ring.

The values of the shielding constants of the macrocyclic triamines (Table 3 ) are generally very dependent on various factors, such as $\mathrm{pH}$ (protonation state, $n$ ), macrocyclic ring size and type of proton considered (e.g. methylenic group) within each molecule. This situation is quite different from what has been observed for linear polyaminocarboxylates, ${ }^{40}$ where constant shielding constants and additive protonation effects of the various basic sites were often observed throughout the whole $\mathrm{pH}$ range. The presently observed dependence of the shielding constants on multiple factors, similar to the one previously recorded for triaza ${ }^{20}$ and tetraaza ${ }^{9,11}$ macrocyclic ligands, results from the existence of $\mathrm{pH}$-dependent preferred conformations of these small macrocyclic molecules, which cause the various substituents not to maintain constant average 

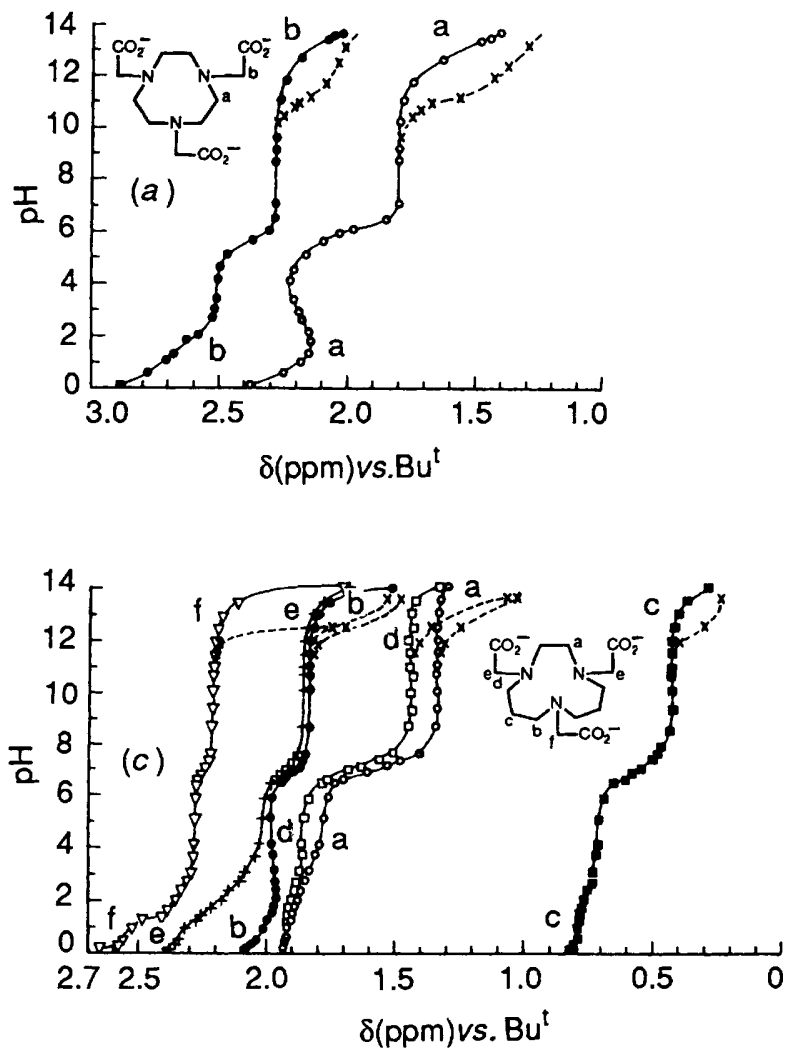
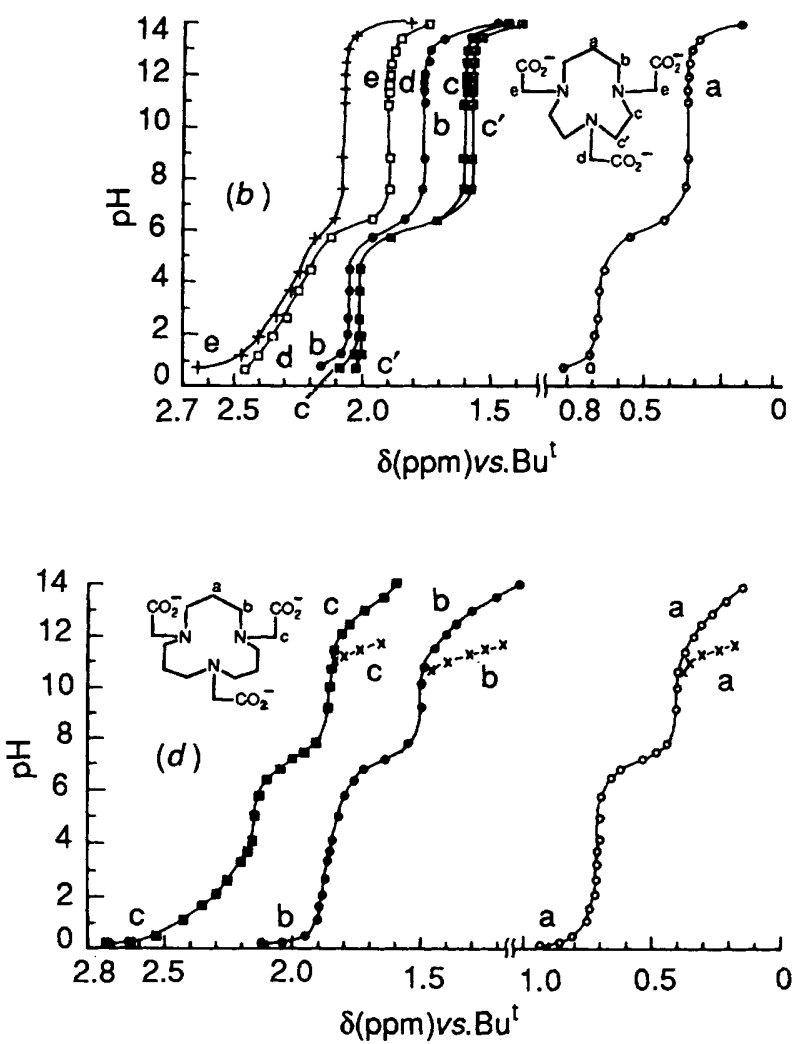

Fig. $4{ }^{1} \mathrm{H}$ NMR titration curves for the triaza macrocyclic tricarboxylate ligands: $(a)$ NOTA; $(b)$ DETA; $(c)$ UNTA; $(d)$ DOTRA. The full curves correspond to the use of KOD, and the dotted curves to the use of NaOD.

Table 2 Protonation constants of triaza macrocyclic ligands, obtained by NMR pH titrations $\left(25^{\circ} \mathrm{C}\right)^{a}$

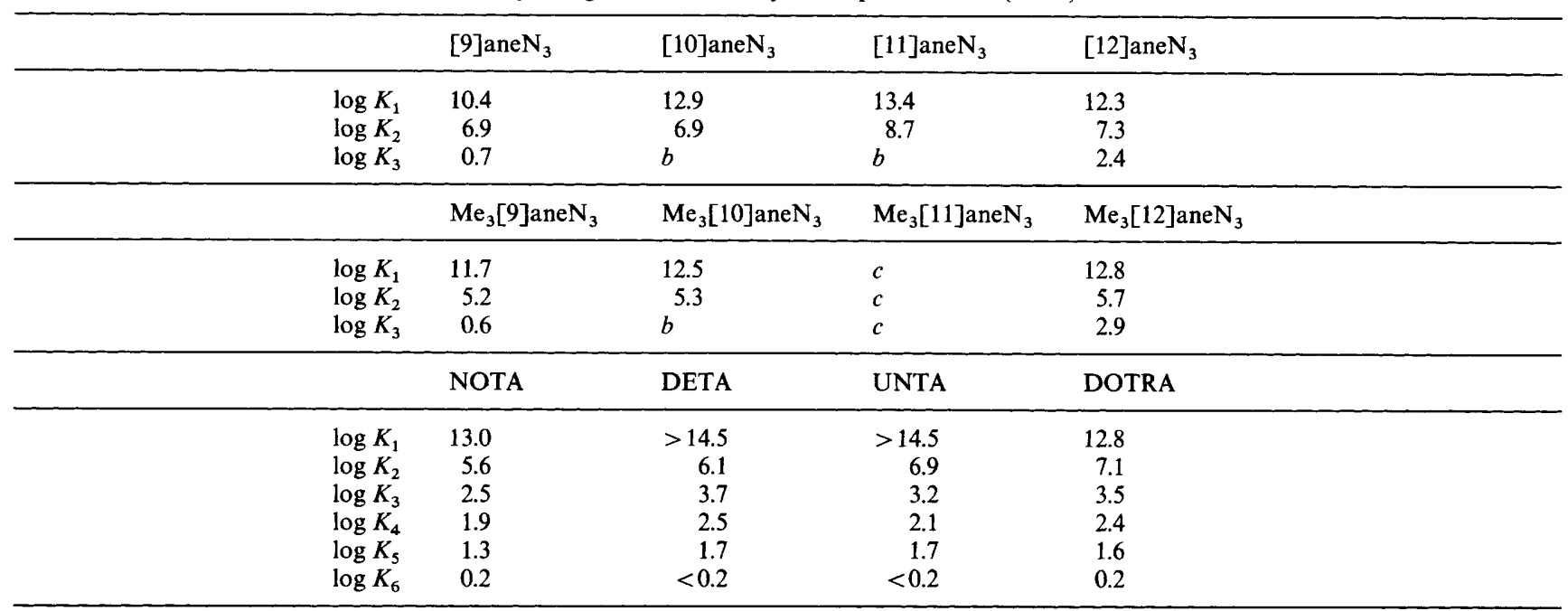

${ }^{a}$ The error of $\log K_{i}$ values is \pm 0.1 units. ${ }^{b}$ Not calculated. ${ }^{c}$ Not studied because the compound could not be synthesized.

relative orientations throughout the whole $\mathrm{pH}$ range. This leads to deviations from the protonation shift additivity which is the basis of the Sudmeier and Reilley's analysis. ${ }^{40}$

We observe no general trend for the $\mathrm{pH}$ dependence of $C_{\mathrm{N}}$ and $C_{N^{\prime}}$ for methylene groups, which may increase, decrease or remain constant, when the $\mathrm{pH}$ decreases, and their values are sometimes much larger or much smaller than those expected for linear and larger macrocyclic amines. Furthermore, these constants show no obvious general decrease when the ring size increases. In the asymmetric amines, the values of $C_{\mathrm{N}}$ and $C_{\mathrm{N}^{\prime}}$ for $n=1$ are considerably higher for the neighbouring $\mathrm{CH}_{2}$ groups of the propane than of the ethane chains, but not for $n \geq 2$ (see Table 3). These observations result from the effect that the increase in size of the macrocyclic ring has on its flexibility and conformational preferences. Protonation of one nitrogen next to a propane chain, for instance, can lead, through internal hydrogen bonding, to a stable chair-preferred conformation for the resultant six-membered ring, which causes an increase in the value of $\log K_{1}$ (such as in [9] ane $\mathrm{N}_{3}$ versus the larger amines, or NOTA versus DETA, UNTA or DOTA, see Table 2). This conformational effect also increases the shielding constants, as a result of a larger effect of the positive charge at the neighbouring nitrogen atoms. The through-space effect of any positive charge at the third nitrogen atom could also be much greater than anticipated if the middle $\mathrm{CH}_{2}$ group at the locked propane chain approached it in space from below the ring, 
Table 3 Shielding constants (ppm) and fractional protonations calculated from the ${ }^{1} \mathrm{H}$ NMR pH titration curves of various cyclic amines

\begin{tabular}{|c|c|c|c|c|c|c|c|c|}
\hline Molecule & $\begin{array}{l}\text { Proton } \\
\text { type }^{c}\end{array}$ & $n$ & $\left(C_{\mathrm{N}}+C_{\mathrm{N}^{\prime}}\right)^{a}$ & $C_{\mathrm{N}}$ & $C_{\mathrm{N}^{\prime}}$ & $C_{\mathrm{N}}{ }^{m}$ & $f_{\mathrm{N}}$ & $f_{N^{\prime}}$ \\
\hline \multirow{3}{*}{ [9] $\operatorname{aneN}_{3}$} & \multirow[t]{3}{*}{$\mathbf{a}$} & 1 & 1.02 & $b$ & $b$ & 一 & 0.33 & 0.33 \\
\hline & & 2 & 1.05 & $b$ & $b$ & - & 0.67 & 0.67 \\
\hline & & 3 & 0.96 & $b$ & $b$ & - & 1.00 & 1.00 \\
\hline \multirow{2}{*}{$\mathrm{Me}_{3}[9] \mathrm{aneN}_{3}$} & \multirow[t]{2}{*}{$a, b$} & 1 & 1.08 & $b$ & $b$ & 0.51 & 0.33 & 0.33 \\
\hline & & 2 & 0.87 & $b$ & $b$ & 1.56 & 0.67 & 0.67 \\
\hline \multirow{4}{*}[10]{$^{a n e} \mathrm{~N}_{3}$} & \multirow{2}{*}{$\mathrm{a}, \mathrm{b}, \mathrm{c}^{\prime}$} & 1 & 1.15 & 0.89 & 0.26 & - & 0.14 & 0.43 \\
\hline & & 2 & 0.82 & 0.53 & 0.29 & - & 0.42 & 0.79 \\
\hline & \multirow[t]{2}{*}{ c } & 1 & $b$ & 0.51 & $b$ & - & $b$ & $b$ \\
\hline & & 2 & $b$ & 0.53 & $b$ & - & $b$ & $b$ \\
\hline \multirow{4}{*}{$\mathrm{Me}_{3}[10] \operatorname{aneN}_{3}$} & \multirow[t]{2}{*}{$\mathrm{a}, \mathrm{b}, \mathrm{d}, \mathrm{e}$} & 1 & 0.76 & 0.58 & 0.18 & 0.54 & 0.24 & 0.38 \\
\hline & & 2 & 1.26 & 0.84 & 0.42 & 0.75 & 0.34 & 0.83 \\
\hline & \multirow{2}{*}{$\mathrm{c}, \mathrm{c}^{\prime}$} & 1 & $b$ & 0.18 & $b$ & $b$ & $b$ & $b$ \\
\hline & & 2 & $b$ & 1.10 & $b$ & $b$ & $b$ & $b$ \\
\hline \multirow{4}{*}{11 aneN $_{3}$} & \multirow[t]{2}{*}{$\mathrm{b}, \mathrm{c}, \mathrm{d}$} & 1 & 1.18 & 0.94 & 0.24 & - & 0.52 & 0.24 \\
\hline & & 2 & 1.12 & 0.73 & 0.39 & - & 0.74 & 0.63 \\
\hline & \multirow[t]{2}{*}{ a } & 1 & 0.38 & $b$ & $b$ & - & $b$ & $b$ \\
\hline & & 2 & 1.08 & $b$ & $b$ & - & $b$ & $b$ \\
\hline \multirow[t]{3}{*}[12]{$\operatorname{aneN}_{3}$} & \multirow[t]{3}{*}{$a, b$} & 1 & 0.86 & 0.72 & 0.14 & - & 0.33 & 0.33 \\
\hline & & 2 & 1.29 & 0.87 & 0.42 & - & 0.67 & 0.67 \\
\hline & & 3 & 1.32 & 0.75 & 0.57 & - & 1.00 & 1.00 \\
\hline \multirow[t]{3}{*}{$\mathrm{Me}_{3}[12]$ ane $\mathrm{N}_{3}$} & \multirow[t]{3}{*}{$a, b, c$} & 1 & 1.31 & 0.90 & 0.41 & 0.63 & 0.33 & 0.33 \\
\hline & & 2 & 1.64 & 1.14 & 0.50 & 0.99 & 0.67 & 0.67 \\
\hline & & 3 & 1.31 & 1.02 & 0.29 & 0.81 & 1.00 & 1.00 \\
\hline
\end{tabular}

${ }^{a}$ The sum $\left(C_{\mathrm{N}}+C_{\mathrm{N}}\right)$ is included in this Table for comparison purposes, because separate $C_{\mathrm{N}}$ and $C_{\mathrm{N}^{\prime}}$ values could not be obtained in some cases, e.g. for protons a of [9] aneN ${ }_{3} \cdot{ }^{b}$ Not calculated. ${ }^{c}$ The subdivisions of proton types into groups reflect the mathematical procedure to calculate the shielding constants.

thus increasing its $C_{\mathrm{N}^{\prime}}$ value [e.g. $C_{\mathrm{N}^{\prime}}$ for protons $\mathrm{CH}_{2}(\mathrm{a})$ in [12] $\mathrm{aneN}_{3}$, see Table 3]. We also observe that the protonation shifts of the methyl groups $\left(C_{\mathrm{N}}^{m}\right)$ increase as the macrocycle becomes protonated, especially for the smaller rings (e.g. $\mathrm{Me}_{3}[9]$ ane $\mathrm{N}_{3}$, Table 3). This is in agreement with the view ${ }^{43}$ that the methylated cyclic amines do not form strong intramolecular hydrogen bonds when an amine group is protonated, which causes the methyl groups to be preferentially directed towards the inside of the ring, therefore experiencing a larger shielding effect due to the nearby positively-charged nitrogens. ${ }^{20}$

The unusual conformational preferences of the various protonated forms of these macrocyclic rings lead to observed $\mathrm{pH}$ dependences of the linewidths of some of their ${ }^{1} \mathrm{H}$ NMR resonances. ${ }^{9,11}$ This was observed in the methylated cyclic triamines (although not in the non-methylated amines) where the $\mathrm{CH}_{2}$ resonances of the ethane and propane ring chains are sharp for the unprotonated form $\mathrm{L}$, but become increasingly broader for the partially protonated forms $\mathrm{HL}^{+}$and $\mathrm{H}_{2} \mathrm{~L}^{2+}$. These resonances generally sharpen at higher temperatures. The linewidths of the methyl resonances, however, remain unaffected by protonation. This process is most probably caused by slow interconversion between the various ring conformations due to slow nitrogen inversion in the partially protonated forms. The presence of the bulky methyl substituents at the nitrogen atoms may not only slow down the nitrogen inversion process, but also increase the chemical shift differences between the $\mathrm{CH}_{2}$ protons in the different conformations, thus causing line broadening.

Triazamacrocyclic Triacetate Ligands.-The ${ }^{1} \mathrm{H}$ NMR spectra of NOTA, DETA, UNTA and DOTRA were assigned on the basis of their signal intensities and multiplicities and also by comparison with the unsubstituted cyclic amines (Fig. 2). Their ${ }^{1}$ H NMR pH titrations curves (Fig. 4) show various inflections due to the $\mathrm{CH}_{2}$ chemical shifts of the ethane and propane chains of the rings and of the acetate groups, due to stepwise protonation of the nitrogen and carboxylate basic sites. The first two protonations result in deshielding of all of the $\mathrm{CH}_{2}$ protons, to different extents. In the absence of $\mathrm{Na}^{+}$ ions, the first inflection is centred at $\mathrm{pH}$ values which are much higher than the first protonation constant of these ligands, obtained by potentiometry in the presence of $\mathrm{Na}^{+}$. For example, the first inflection for NOTA, at pH 13.0, is higher than $\log K_{1}$ measured for NOTA (11.41) in the presence of 0.1 mol dm${ }^{-3} \mathrm{Na}^{+}$. This illustrates the effect of $\mathrm{Na}^{+}$binding to the macrocycle, which has previously been shown ${ }^{22}$ to consist of a marked decrease in the first protonation constant, when the $\mathrm{Na}^{+}$concentration in the medium increases.

The percentage protonation of the nitrogen atoms, $f_{\mathrm{N}}$ and $f_{\mathrm{N}^{\prime}}$, and of the carboxylic oxygen atoms, $f_{\mathrm{O}}$ and $f_{\mathrm{O}^{\prime}}$, of the macrocyclic complexones can be calculated using Sudmeier and Reilley's analysis. ${ }^{40}$ However, using the shielding constants derived from the cyclic triamines or their trimethylated derivatives (Table 3 ), very large or occasionally even negative values of $f_{\mathrm{N}}, f_{\mathrm{N}^{\prime}}, f_{\mathrm{O}}$ and $f_{\mathrm{O}^{\prime}}$ are obtained, with very large error limits. ${ }^{11}$ This again shows that the methylated cyclic amines are very poor models for the carboxylate derivatives of identical ring size. ${ }^{9,11}$ It has previously been shown ${ }^{20}$ that the first 2 equiv. of acid added to NOTA protonate exclusively the three nitrogen atoms. That can also be assumed to be the case for the other complexones, because the first two $\log K_{i}$ values of DETA, UNTA and DOTRA are higher than those of NOTA (see Table 1). Therefore, the shielding constants in the first two protonation stages ( $n=1$ and 2) can be calculated, as well as the protonation percentages, $f_{\mathrm{N}}$ and $f_{\mathrm{N}^{\prime}}$

The calculated values of $f_{\mathrm{N}}$ and $f_{\mathrm{N}^{\prime}}$ (Table 4) show that, whereas in the symmetric complexones NOTA and DOTRA the three nitrogen atoms are equally protonated, in the asymmetric complexones, DETA and UNTA, there are preferential protonations. The first protonation is predominant where sixmembered rings can be formed by internal hydrogen bonding ( $\mathrm{N}^{\prime}$ of DETA and N of UNTA, see Fig. 1 and Table 4), while after the second protonation the three percentages are almost equal.

The calculated values of $C_{\mathrm{N}}$ and $C_{\mathrm{N}^{\prime}}$ for the complexones are, in the case of the cyclic triamines previously discussed, highly dependent on $\mathrm{pH}$, ring size and type of proton considered. This, again, is a result of the complex $\mathrm{pH}$-dependent conformational 

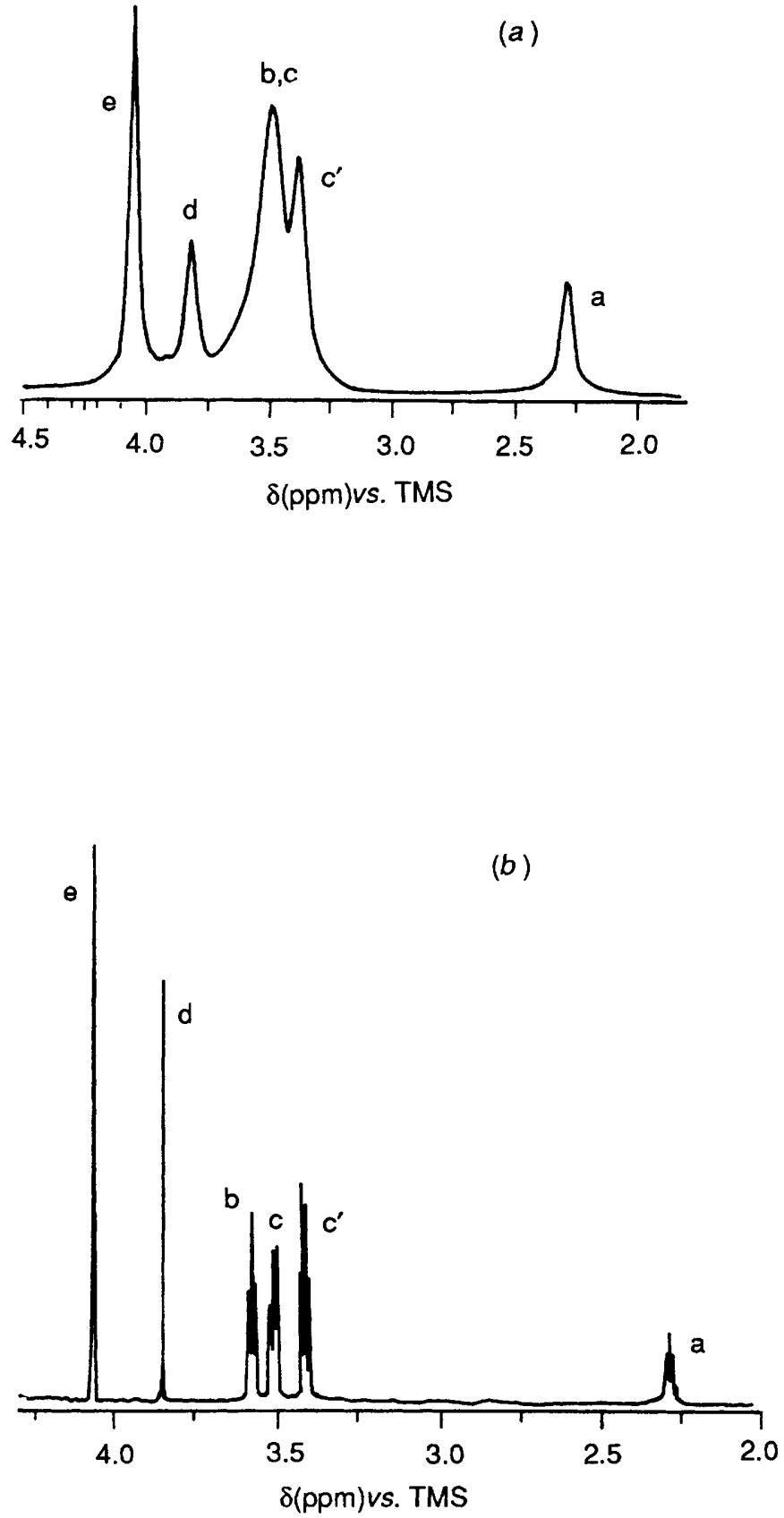
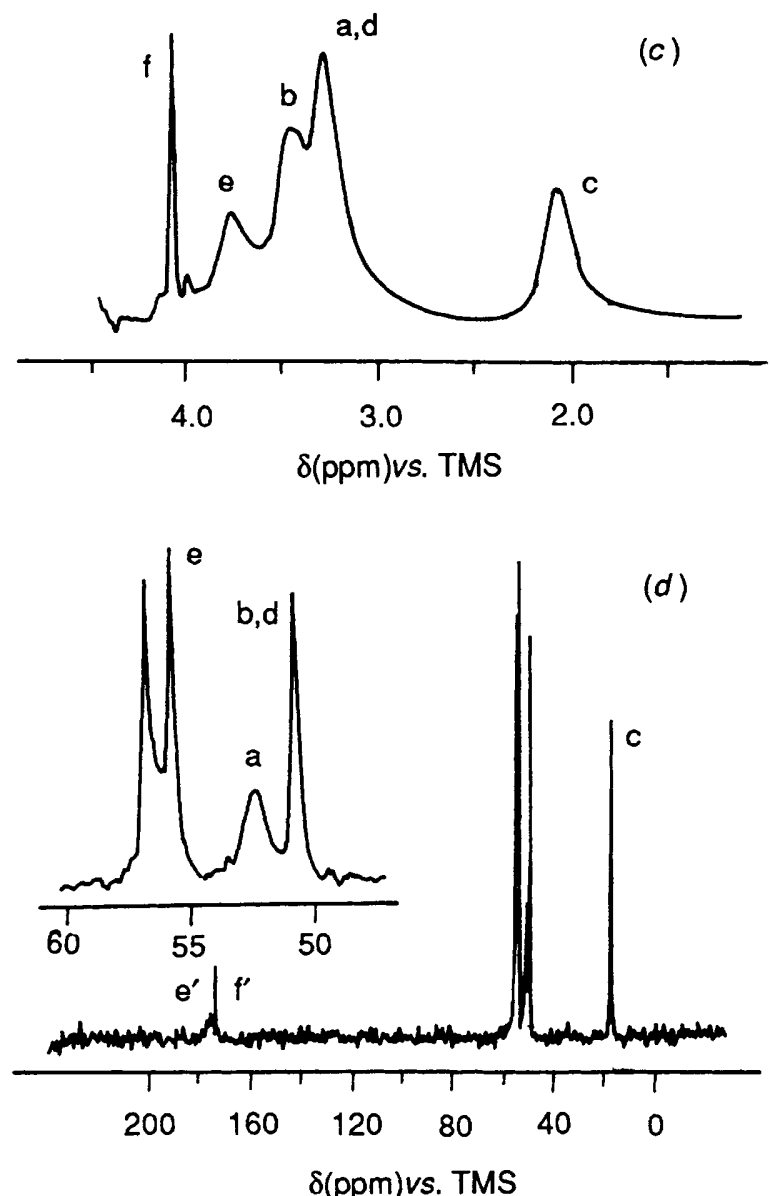

$(e)$

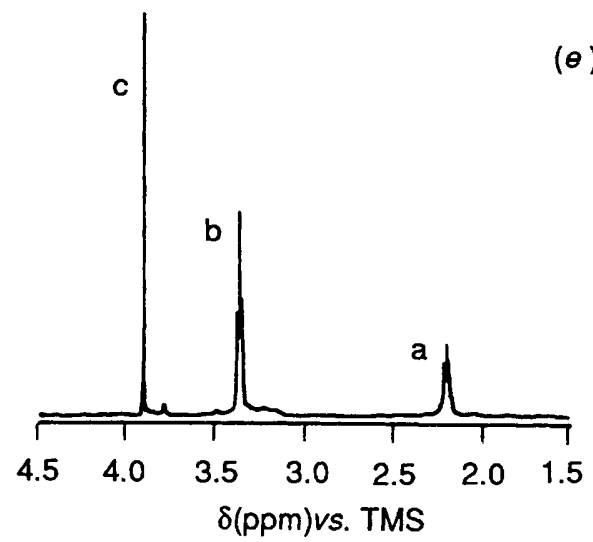

Fig. 5 NMR spectra of the acid form of the complexones in $\mathrm{D}_{2} \mathrm{O}$. Proton spectrum of DETA, pH $=1.0:(a)$ at $25^{\circ} \mathrm{C} ;(b)$ at $80^{\circ} \mathrm{C}$. Spectra of UNTA, $\mathrm{pH}=1.0$, at $25^{\circ} \mathrm{C} ;(c){ }^{1} \mathrm{H}$ spectrum; $(d){ }^{13} \mathrm{C}$ spectrum. (e) Proton spectrum of DOTRA, $\mathrm{pH}=1.2$, at $25^{\circ} \mathrm{C}$ [proton spectra $(a)$ and $(b)$ were obtained at $500 \mathrm{MHz},(c)$ and $(e)$ at $200 \mathrm{MHz} ;{ }^{13} \mathrm{C}$ spectrum $(d)$ was obtained at $50.1 \mathrm{MHz}$.

equilibria of those complexones. Apart from the effects present in the parent amines, other effects can arise specifically for the complexones. These include the possibilities of hydrogen bonding between protonated nitrogens and non-protonated carboxylates or protonated carboxylates and non-protonated nitrogens. ${ }^{9,11,19,20}$ These effects may cause proton shift anomalies, such as the ones detected in $\mathrm{CH}_{2}$ groups of ethane bridges [Fig. 4(a)], ${ }^{9,20,40}$ or may slow down the rates of nitrogen inversion, as indeed is observed through broadening effects on the ${ }^{1} \mathrm{H}$ and ${ }^{13} \mathrm{C}$ NMR spectra of the acid forms of the asymmetric complexones DETA and UNTA, although not for the symmetric ones, NOTA and DOTRA (Fig. 5). These broadening effects disappear at high temperatures [Fig. 5(a), (b)]. In the case of UNTA, for example, specific broadening is observed for the ${ }^{13} \mathrm{C}$ resonances of the carboxylate and $\mathrm{CH}_{2}$ carbons of the acetate groups e and the $\mathrm{CH}_{2}$ groups a of the ethane bridge. These effects reflect the slow rate of inversion of the two nitrogen atoms $\mathrm{N}^{\prime}$ due to the two types of intramolecular hydrogen bonding interactions referred to above, which involve the acetate arms e and the two nitrogen atoms $\mathrm{N}^{\prime}$. Although these intramolecular processes cannot be studied in detail due to their complexity, a quantitative analysis of the NMR titration curve of Fig. 4(c) shows that, at pH ca. 1.0, the three carboxylate atoms and the three nitrogen groups are all partially protonated ( $n c a$. 4), but with preferential protonation at $\mathrm{N}$ and at the acetate arms e (see later and the fractional protonations of Table 6). These proton distributions are compatible with the types of process discussed above.

The difficulties of using Sudmeier and Reilley's method to obtain the percentage protonations of the triaza macrocyclic 
Table 4 Values of $C_{\mathrm{N}}$ and $C_{\mathrm{N}^{\prime}}(\mathrm{ppm})$ and fractional protonations calculated for the various cyclic triaminocarboxylic acids at $n=1(n=2$ in parentheses)

\begin{tabular}{|c|c|c|c|c|c|c|}
\hline Molecule & $\begin{array}{l}\text { Proton } \\
\text { type }\end{array}$ & $C_{\mathrm{N}}$ & $C_{\mathrm{N}^{\prime}}$ & $f_{\mathrm{N}}$ & $f_{\mathrm{N}}$ & $f_{\mathrm{o}}, f_{\mathrm{O}^{\prime}}$ \\
\hline NOTA & $a, b$ & $0.85(0.70)$ & $0.42(0.66)$ & $0.33(0.67)$ & $0.33(0.67)$ & $0(0)$ \\
\hline \multirow[t]{4}{*}{ DETA } & $\mathrm{a}$ & - & $0.42(0.61)$ & & & \\
\hline & b & $0.92(1.12)$ & & & & \\
\hline & $c, c^{\prime}$ & $0.30(0.85)$ & $0.42(0.40)$ & & & \\
\hline & $\mathrm{d}, \mathrm{e}$ & $0.79(0.48)$ & - & $0.24(0.72)$ & $0.38(0.64)$ & $0(0)$ \\
\hline \multirow[t]{3}{*}{ UNTA } & a & $\left(C_{\mathrm{N}}+C_{\mathrm{N}}\right)$ & $0.20(1.07)$ & & & \\
\hline & $b, d$ & $0.53(0.98)$ & & & & \\
\hline & c & $\overline{0}$ & $0.31(0.43)$ & $060>76$ & $020(062)$ & $0(0)$ \\
\hline \multirow[t]{3}{*}{ DOTRA } & $\begin{array}{l}e, t \\
a\end{array}$ & ${ }^{0.94(0.38)}$ & $\overline{0.39}(0.45)$ & $0.00(0.10)$ & & $0(0)$ \\
\hline & $\mathrm{b}$ & $1.17(0.96)$ & - & $0.33(0.67)$ & $0.33(0.67)$ & $0(0)$ \\
\hline & c & $0.87(0.81)$ & - & & & \\
\hline
\end{tabular}

Table 5 Fractional protonations of nitrogen atoms and carboxylate groups in the symmetric complexones NOTA and DOTRA, as a function of the number of protons added

\begin{tabular}{|c|c|c|c|c|}
\hline \multirow[b]{2}{*}{$n$} & \multicolumn{2}{|c|}{ NOTA } & \multicolumn{2}{|c|}{ DOTRA } \\
\hline & $f_{\mathrm{N}}$ & $f_{\mathrm{o}}$ & $f_{\mathrm{N}}$ & $f_{\mathrm{o}}$ \\
\hline 1 & 0.33 & 0.00 & 0.33 & 0.00 \\
\hline 2 & 0.67 & 0.00 & 0.67 & 0.00 \\
\hline 3 & 0.67 & 0.33 & 0.67 & 0.33 \\
\hline 4 & 0.67 & 0.66 & 0.67 & 0.66 \\
\hline 5 & 0.73 & 0.94 & 0.69 & 0.98 \\
\hline
\end{tabular}

Table 6 Fractional protonations of nitrogen atoms and carboxylate groups in the asymmetric complexones DETA and UNTA, as a function of the number of protons added

\begin{tabular}{|c|c|c|c|c|c|c|c|c|}
\hline \multirow[b]{2}{*}{$n$} & \multicolumn{4}{|c|}{ DETA } & \multicolumn{4}{|c|}{ UNTA } \\
\hline & $f_{\mathrm{N}}$ & $f_{\mathrm{N}^{\prime}}$ & $f_{\mathrm{o}}$ & $f_{\mathrm{O}^{\prime}}$ & $f_{\mathrm{N}}$ & $f_{\mathrm{N}^{\prime}}$ & $f_{\mathrm{o}}$ & $f_{\mathbf{O}^{\prime}}$ \\
\hline 1 & 0.24 & 0.38 & 0.00 & 0.00 & 0.60 & 0.20 & 0.00 & 0.00 \\
\hline 2 & 0.72 & 0.64 & 0.00 & 0.00 & 0.76 & 0.62 & 0.00 & 0.00 \\
\hline 3 & 0.72 & 0.64 & 0.32 & 0.34 & 0.76 & 0.62 & 0.16 & 0.42 \\
\hline 4 & 0.72 & 0.64 & 0.60 & 0.75 & 0.76 & 0.62 & 0.34 & 0.83 \\
\hline 5 & 0.78 & 0.67 & 0.88 & 1.00 & 0.80 & 0.67 & 0.86 & 1.00 \\
\hline
\end{tabular}

complexones from shielding constants, for values of the number of moles of added protons $n>2$, are similar to those found for the tetraaza ligands. ${ }^{11} \mathrm{We}$ assumed that the shielding constants $C_{\mathrm{N}}$ and $C_{\mathrm{N}^{\prime}}$, for each type of proton of the four triaza complexones studied in this work, have the same $\mathrm{pH}$ dependence of the corresponding protons of the tetraaza ligands, ${ }^{11}$ since the processes of hydrogen bond formation for $n>2$ are similar in both cases, and depend on the probability of protonation of the carboxylate groups, $f_{\mathrm{o}}$. This may be expressed, e.g. for $C_{\mathrm{N}}$, by the equation $C_{\mathrm{N}}(n>2)=C_{\mathrm{N}}(n=2)$ $+\alpha f_{\mathrm{O}}$. The value of $\alpha$ was calculated to be 0.3 for the acetate groups, 0.05 for the methylene protons of ring propane chains and 0.1 for those of the ring ethane chains. ${ }^{11}$ Taking these assumptions and the values of $C_{\mathrm{N}}$ and $C_{\mathrm{N}^{\prime}}$ for $n=2$ (Table 4), we proceeded to estimate the entire sequence of protonation of the four ligands, for $n=3-5$. The results obtained (with deviations $<5 \%$ ) are shown in Tables 5 and 6 . It was observed that for all the ligands, after the first 2 equiv. of acid have protonated only the nitrogen, the next 2 equiv. protonate exclusively the carboxylate groups. The fifth acid equiv. still adds preferentially, although not exclusively, to the carboxylates. The percentage protonation of the ring nitrogens, achieved at $n=5$, increases for the larger rings. For the asymmetric complexones DETA and UNTA, preferential protonation of the ring nitrogens for $n=1,2$ (see discussion above) is followed, for $n=3,4$, by preferential protonation at the acetate arms bound to the least protonated nitrogens $\left(f_{\mathrm{O}^{\prime}}>f_{\mathrm{O}}, f_{\mathrm{N}}>f_{\mathrm{N}^{\prime}}\right.$, see Table 6$)$. This observation suggests that the preferential formation of hydrogen bonds in these small chelates occurs between protonated nitrogens and nonprotonated carboxylates of the pendant arm bound to them, as this process renders the hydrogen-bonded carboxylate groups less basic.

Finally, we obtained protonation constants for these complexones from their NMR protonation percentages (Table 2), that were taken as the $\mathrm{pH}$ values at which $n$ is half-integral. Values of $\log K_{3}$ and $\log K_{4}$ agree reasonably well with the results obtained from potentiometry (Table 1). Values of log $K_{5}$, and even very low values of $\log K_{6}$ (largely corresponding to total ring nitrogen protonation), were also obtained (Table 2).

\section{Conclusions}

The use of Sudmeier and Reilley's method ${ }^{40}$ to determine the protonation sequences of small macrocyclic ligands ${ }^{11}$ is complicated by the unusual conformational behaviour of these cyclic compounds, much more complex than their linear polyaminocarboxylate analogues, for which the method was originally developed. The shielding constants $C_{\mathrm{N}}$ and $C_{\mathrm{N}^{\prime}}$ of the methylene protons continuously increase with $\mathrm{pH}$ and are different for different types of protons. We analysed, by ${ }^{1} \mathrm{H}$ and ${ }^{13} \mathrm{C}$ NMR spectroscopy, some of the origins of these conformational properties of the assymmetric complexones. Their restricted flexibility results from changing electrostatic and hydrogen bond interactions, as the various groups are protonated. $^{11}$

Previously proposed ${ }^{11}$ empirical relations for the $\mathrm{pH}$ dependence of the $C_{\mathrm{N}}$ and $C_{\mathrm{N}^{\prime}}$ shielding parameters proved useful for the small triaza macrocyclic complexones, allowing detailed microscopic interpretation of their macroscopic protonation constants.

The very high values of the first protonation constant of the complexones, which are very sensitive to the presence of $\mathrm{Na}^{+}$in the medium, reflect their slow and difficult first deprotonation, particularly of the larger ligands UNTA and DOTRA. ${ }^{25}$ This deprotonation step may be rate determining in the process of binding of these chelates to metal ions ${ }^{25,44}$ and may also affect the thermodynamic stability of the complexes formed. This problem is under further investigation.

\section{Acknowledgements}

This work was supported in part by grants from the Robert 
A. Welch Foundation (AT-584), Mallinckrodt, Inc., USA, as well as from INIC, Portugal. C. F. G. C. G. acknowledges a Fulbright grant and support from the Luso-American Foundation.

\section{References}

1 A. D. Sherry and C. F. G. C. Geraldes, Lanthanide Probes in Life, Medical and Environmental Sciences: Theory and Practice, eds. Bunzli and Choppin, Elsevier, Amsterdam, 1989.

2 J. F. Desreux and P. P. Barthelemy, Nucl. Med. Biol., 1988, 15, 9.

3 C. A. Chang, V. O. Ochaya and V. C. Sekhar, J. Chem. Soc., Chem. Commun., 1985, 1794

4 C. A. Chang and V. O. Ochaya, Inorg. Chem., 1986, 25, 355

5 V. C. Sekhar and C. H. Chang, Inorg. Chem., 1986, 25, 2061

6 V. K. Manchanda and C. A. Chang, Anal. Chem., 1987, 59, 813.

7 C. A. Chang and M. E. Rowland, Inorg. Chem., 1983, 22, 3866.

8 C. A. Chang and V. C. Sekhar, Inorg. Chem., 1987, 26, 1981.

9 J. F. Desreux, E. Merciny and M. F. Loncin, Inorg. Chem., 1981, 20, 987.

10 R. Delgado and J. J. R. Frausto da Silva, Talanta, 1982, 29, 815.

11 J. R. Ascenso, R. Delgado and J. J. R. Frausto da Silva, J. Chem. Soc., Perkin Trans. 2, 1985, 781.

12 J. F. Desreux, Inorg. Chem., 1980, 19, 1319.

13 C. C. Bryden, C. N. Reilley and J. F. Desreux, Anal. Chem., 1981, 53 1918.

14 J. R. Ascenso, R. Delgado and J. J. R. Frausto da Silva, J. Chem. Soc., Dalton Trans., 1986, 2395.

15 T. Arishima, K. Hamada and S. Takamoto, Nippon Kagaku Kaishi, 1973, 1119; H. Hama and S. Takamoto, Nippon Kagaku Kaishi, 1975, 1182.

16 M. Takahashi and S. Takamoto, Bull.Chem. Soc. Jpn., 1977, 50, 3413.

17 K. Wieghardt, U. Bossek, P. Chanduri, W. Herrmann, B. C. Menke and J. Weiss, Inorg. Chem., 1982, 21, 4308.

18 M. J. van der Merwe, J. Boeyens and R. D. Hancock, Inorg. Chem., 1983, 22, 3490; Inorg. Chem., 1985, 25, 1208.

19 M. J. van der Merwe, F. C. A. Boyens and R. D. Hancock, Inorg. Chem., 1985, 24, 1208.

20 C. F. G. C. Geraldes, M. C. Alpoim, M. P. M. Marques, A. D. Sherry and M. Singh, Inorg. Chem., 1985, 24, 3876.

21 A. D. Sherry, M. Singh and C. F. G. C. Geraldes, J. Magn. Reson., 1986, 66, 511 .
22 A. Bevilaqua, R. I. Gelb, W. B. Hebard and L. J. Zompa, Inorg. Chem., 1987, 26, 2699.

23 W. P. Cacheris, S. K. Nickle and A. D. Sherry, Inorg. Chem., 1987, 26, 958.

24 C. F. G. C. Geraldes, A. D. Sherry, R. D. Brown III and S. H. Koenig, Magn. Res. Med., 1986, 3, 242.

25 S. Cortes, E. Brucher, C. F. G. C. Geraldes and A. D. Sherry, Inorg. Chem., 1990, 29, 5.

26 H. Koyama and T. Yoshino, Bull. Chem. Soc. Jpn., 1972, 481

27 R. Yang and L. J. Zompa, Inorg. Chem., 1976, 15, 1499.

28 M. Kodama and E. Kimura, Yuki Gosei Kagaku Kyokaishi, 1977, 35, 632.

29 L. J. Zompa, Inorg. Chem., 1978, 17, 2531.

30 T. J. Reido and T. A. Kaden, Helv. Chim. Acta, 1979, 62, 1089.

31 J. E. Richman and T. J. J. Atkins, J. Am. Chem. Soc., 1974, 96, 2268.

32 J. T. Atkins, J. E. Richman and W. F. Oetle, Org. Synth., 1978, 58, 86.

33 D. W. White, B. A. Karcher, P. A. Jacobson and J. G. Verkade, J. Am. Chem. Soc., 1979, 101, 4921.

34 A. E. Martin, T. M. Ford and J. E. Bulkowski, J. Org. Chem., 1982, $47,412$.

35 G. H. Searle and R. J. Gene, Aust. J. Chem., 1984, 37, 959.

36 F. Chavez and A. D. Sherry, J. Org. Chem., 1989, 54, 2990.

37 M. S. Caceci and W. P. Cacheris, Byte, 1984, 5, 340.

38 P. K. Glasoe and F. A. Long, J. Phys. Chem., 1960, 64, 188.

39 C. F. G. C. Geraldes, A. D. Sherry and W. P. Cacheris, Inorg. Chem $1989,28,3336$.

40 J. L. Sudmeier and C. N. Reilley, Anal. Chem., 1964, 36, 1698.

41 M. Micheloni, A. Sabatini and P. J. Paoletti, J. Chem. Soc., Pert * Trans. 2, 1978, 828.

42 M. Micheloni, P. Paoletti and A. Vacca, J. Chem. Soc., Perkin Trans. $2,1978,945$.

43 J. F. Desreux and G. Duyckaerts, Inorg. Chim. Acta, 1979, 35, 1313

44 A. S. Craig, I. M. Helps, K. J. Jankowski, D. Parker, N. R. A. Beeley, B. A. Boyce, M. A. W. Eaton, A. T. Millican, K. Millar, A. Phipps, S. K. Rhind, A. Harrison and C. Walker, J. Chem. Soc., Chem. Commun., 1989, 794.
Paper 9/05186D

Received 5th December 1989 Accepted 22nd August 1990 